\title{
Automatic regulation of the endotracheal tube cuff pressure with a portable elastomeric device. A randomized controlled study
}

Jérôme E Dauvergne ( $\sim$ jerome.dauvergne@chu-nantes.fr)

Centre Hospitalier Universitaire de Nantes https://orcid.org/0000-0002-9687-1059

Anne-Laure GEFFRAY

Centre Hospitalier Universitaire de Nantes

Karim ASEHNOUNE

Centre Hospitalier Universitaire de Nantes

Bertrand ROZEC

Centre Hospitalier Universitaire de Nantes

Karim LAKHAL

Centre Hospitalier Universitaire de Nantesf

\section{Research}

Keywords: Cuff pressure, Underinflation, Intubation, Intratracheal [MeSH] Manometer, Pneumonia, Aspiration [MeSH], Smart Cuffmanager

Posted Date: January 21st, 2020

DOI: https://doi.org/10.21203/rs.2.20957/v1

License: (c) (i) This work is licensed under a Creative Commons Attribution 4.0 International License. Read Full License 


\section{Abstract}

\section{Background}

Endotracheal tube cuff underinflation contributes to microaspiration of contaminated oropharyngeal content, source of pneumonia. Overinflation exposes to airway damage. Intermittent manual adjustment of the cuff pressure (P cuff ) may delay the detection of under- or overinflation. Devices for automated continuous adjustment of $\mathrm{P}$ cuff are promising but some are inconvenient, expensive or even harmful. This prospective randomized controlled study tested whether the Tracoe Smart Cuff Manager TM reduced the rate of patients undergoing $\geq 1$ episode of underinflation ( $P$ cuff $<20 \mathrm{cmH} 20$ ), as compared with routine manual $\mathrm{P}$ cuff adjustment. Secondary endpoints included comparisons of the rate of patients with $\geq 1$ overinflation episode ( $P$ cuff $>30 \mathrm{cmH} 20$ ), of the incidence of under- and overinflation episodes and of their magnitude. Methods Patients likely to receive invasive mechanical ventilation for $>48$ hours because of acute brain injury were randomly allocated to receive, during 48 hours, automated $P$ cuff adjustment (combined with manual adjustment) or manual adjustment alone. In each group, P cuff was measured with a dedicated manual manometer, at least every 8 hours.

Results

Sixty patients were analyzed ( 28 patients with automated and 32 with manual $P$ cuff adjustment) for 506 measurements of P cuff (237 and 269, respectively). As compared with manual adjustment, automated adjustment of $\mathrm{P}$ cuff was associated with 1 ) a lower rate of patients with $\geq 1$ episode of underinflation (63\% and $18 \%$, respectively, $\mathrm{p}<0.001), 2)$ a lower incidence of underinflation episodes ( $15 \%$ vs. $2 \% ; p<0.001), 3)$ a lower rate of manual adjustments ( $77 \%$ vs. $56 \% ; p<0.001)$ and 4$)$ manual adjustments of lower magnitude $(5.9 \pm 4.5$ vs. $3.6 \pm 4.7 \mathrm{cmH} 20 ; p<0.001)$. For overinflation, there was no significant between-groups differences ( $p>0.99$ ).

\section{Conclusions}

The adjunction of a continuous P cuff control with the Tracoe Smart Cuff Manager TM to routine manual intermittent adjustment reduced both the incidence of $\mathrm{P}$ cuff underinflation episodes and their magnitude without provoking overinflation.

\section{Background}

Keeping the endotracheal tube cuff pressure $\left(\mathrm{P}_{\text {cuff }}\right)$ between 20 and $30 \mathrm{~cm} \mathrm{H}_{2} \mathrm{O}[1]$ is part of nurse routine care of critically ill patients requiring mechanical ventilation [2,3]. On the one hand, cuff underinflation exposes to the microaspiration of contaminated oropharyngeal content, an important contributor to ventilator-associated pneumonia [2]. On the other hand, cuff overinflation promotes airway (mucosa or cartilage) damage[4]. However, routine intermittent $\mathrm{P}_{\text {cuff }}$ monitoring and adjustment via a manual manometer may not avoid underinflation or overinflation episodes between measurements. Hence, less than one fifth of patients have a correct $\mathrm{P}_{\text {cuff }}$ during the 8 hours between two manual adjustments [5]. 
Besides cuff leakage, changes in the airway tone or in patient's position can alter $\mathrm{P}_{\text {cuff }}$ between intermittent adjustments [6]. Episodes of under- or overinflation are therefore often overlooked or detected [5]

To achieve a correct $\mathrm{P}_{\text {cuff }}$ over 24 hours a day, devices for continuous monitoring of $\mathrm{P}_{\text {cuff }}$ have been developed and marketed. Encouraging findings were reported with these devices (blurry, provide a result) [7]. Yet, the amount of data is still too limited to recommend their use [7]. Moreover, these devices are bulky, inconvenient, expensive, and/or need electrical power supply. In addition, some devices may be ineffective and even potentially harmful since not only do they fail in preventing tracheal cuff underinflation as well as they provoke overinflation [8]. For all these reasons, the use of automated $\mathrm{P}_{\text {cuff }}$ regulation is still not widespread [9]. A simple elastomeric device, already on the market, may overcome these issues: the Tracoe Smart Cuff Manager ${ }^{\mathrm{TM}}$ (Tracoe medical GmbH, Nieder-OIm, Germany). Whether it is effective in keeping $\mathrm{P}_{\text {cuff }}$ within the correct range is unknown since no published study assessed this device.

The primary objective of this prospective randomized controlled study was to evaluate whether the adjunction, to routine care, of automatic adjustment of $\mathrm{P}_{\text {cuff }}$ with the Tracoe Smart Cuff Manager ${ }^{\mathrm{TM}}$ reduced the rate of patients undergoing at least one episode of tracheal cuff underinflation $\left(P_{\text {cuff }}<20 \mathrm{~cm}\right.$ $\mathrm{H}_{2} \mathrm{O}$ ), as compared with intermittent manual $\mathrm{P}_{\text {cuff }}$ adjustments. As secondary endpoints, we compared, between the two strategies, the rate of patients with $\geq 1$ overinflation episode $\left(P_{\text {cuff }}>30 \mathrm{~cm} \mathrm{H}_{2} \mathrm{O}\right)$, the incidence of under- and overinflation episodes and their magnitude. The incidence of early respiratory infections, ventilator free days, ICU length of stay and mortality was also examined.

\section{Methods}

\section{Patients}

This prospective randomized controlled study was performed in two ICUs of Nantes University Hospital (16 and 20 beds). Adult patients admitted to the ICU with acute brain injury were included within the first 48 hours of their ICU stay if they were likely to require mechanical ventilation for at least 48 additional hours through orotracheal tube with a low pressure-high volume cuff.

Patients were not included or were excluded if they had a nasotracheal tube or tracheostomy, if there was a change in the upper airway management within the 48 hours following the inclusion (extubation, change in the tracheal tube or tracheostomy). Pregnancy and safeguarding regimen were also noninclusion criteria.

Patients were randomly assigned to receive either solely intermittent manual $P_{\text {cuff }}$ adjustments or their combination with Tracoe Smart Cuff Manager ${ }^{\text {TM }}$-driven automated adjustments (a group subsequently referred to as automated $\mathrm{P}_{\text {cuff }}$ adjustment). Randomization was performed using a 1:1 computergenerated random assignment list. 


\section{$\mathbf{P}_{\text {cuff }}$ monitoring and adjustment}

In both groups, intermittent $P_{\text {cuff }}$ measurements and adjustments were performed with a dedicated manual manometer (Endotest ${ }^{\circledR}$, Rusch ${ }^{\text {TM }}$ Teleflex ${ }^{\circledR}$, Wayne, USA), every 8 hours [11] and immediately before and after intra-hospital transfer [12].

The use of the Tracoe Smart Cuff Manager ${ }^{\mathrm{TM}}$ is detailed in Fig. 1. Briefly, this elastomeric device includes a blue inner balloon. This balloon can either receive air from the tracheal cuff (if the latter is overinflated) or inflate the tracheal cuff (if underinflated). This keeps $\mathrm{P}_{\text {cuff }}$ within the $20-30 \mathrm{~cm} \mathrm{H}_{2} \mathrm{O}$ range.

Immediately after randomization, the Tracoe Smart Cuff Manager ${ }^{\mathrm{TM}}$ was connected to the $\mathrm{P}_{\text {cuff }}$ control port of the endotracheal tube via a three way stopcock in order to avoid repeated disconnections of the device when manometer measurements of $P_{\text {cuff }}$ are performed. Indeed, for a more direct measurement of $P_{\text {cuff }}$ in this study, we chose to measure $P_{\text {cuff }}$ upstream of the Tracoe Smart Cuff Manager ${ }^{\text {Th }}$ rather than using the dedicated air inlet of the device.

The Tracoe Smart Cuff Manager ${ }^{\mathrm{TM}}$ was kept connected 24 hours a day, even during patient transfer (to the imaging facility for instance), for at least 48 hours (the observation period). Its maintenance after the 48th hour was left to the discretion of caregivers.

\section{Study endpoints}

The primary objective was to evaluate whether the Tracoe Smart Cuff Manager ${ }^{\text {TM }}$ reduced the rate of patients undergoing at least one episode of tracheal cuff underinflation $\left(P_{\text {cuff }}<20 \mathrm{~cm} \mathrm{H}_{2} \mathrm{O}\right)$, as compared with intermittent $P_{\text {cuff }}$ adjustments only.

As secondary endpoints, comparisons between the two groups were as follow: the rate of patients undergoing at least one episode of tracheal cuff overinflation $\left(\mathrm{P}_{\text {cuff }}>30 \mathrm{~cm} \mathrm{H} \mathrm{H}_{2} \mathrm{O}\right)$, the incidence of underand overinflation episodes, the rate of $\mathrm{P}_{\text {cuff }}$ adjustments and their magnitude. Ventilator free days, ICU length of stay and mortality and incidence of early respiratory infections were also compared. The latter was defined as the prescription, by the attending physician, of antimicrobial therapy for pneumonia or tracheobronchitis, over at least a 7-day period beginning 48 hours after the randomization. Indeed, an infection occurring within the first 48 hours is likely to be related to aspiration of upper airway content prior to the inclusion rather than to failure of the allocated strategy for $P_{\text {cuff }}$ control. Patients with ongoing antimicrobial therapy for respiratory infection at the beginning of this 7-day period were excluded from this analysis. After careful review of the medical charts, cases of early respiratory infections were adjudicated by a physician blind to the randomization.

\section{Sample size calculation}

A previous study reported that, with no device for automated $\mathrm{P}_{\text {cuff }}$ control, $55 \%$ of patients experienced at least one episode of underinflation within a 48-hour observation period [7]. To detect a Tracoe Smart Cuff 
Manager ${ }^{\text {TM }}$-induced decrease, from 55 to $20 \%$, in the proportion of patients experiencing at least one episode of underinflation, 56 patients were required (two groups of 28), with two-sided tests, an alpha risk of 0.05 and a power of $80 \%$. A $5 \%$ margin yielded a total of 60 patients.

\section{Statistical tests}

Intention-to-treat analyses were performed. Normally and non-normally distributed quantitative parameters were expressed as mean \pm SD or median [interquartile range], respectively. Their comparisons relied on Student's t-test or Mann-Whitney U test, respectively. Qualitative parameters were expressed in count (\%) and compared with Fisher's exact test. The Epi info ${ }^{\text {TM }}$ version 7.2.2.6 (CDC, Atlanta, GA, USA, 2011) and the RStudio version 1.2.1335 (R Foundation for Statistical Computing, Vienna, Austria) softwares were used. A $p<0.05$ was considered significant.

\section{Results}

From March 2018 to July 2019, 65 patients were included. Informed consent could not be obtained in 5 patients. Therefore, 60 patients were analyzed: 28 were allocated to the adjunction of automated $P_{\text {cuff }}$ adjustment, 32 to routine manual adjustments only (Fig. 2).

Overall, 506 measurements of $\mathrm{P}_{\text {cuff }}$ were performed: 237 and 269 in patients with automated and with manual adjustments, respectively (mean of $8.5 \pm 3.5$ and $8.4 \pm 2.4$ measurements per patient).

Most patients' characteristics were similar in the 2 groups except for a few of them, including some airway pressures which were higher in patients with manual $P_{\text {cuff }}$ adjustment (Tables 1 and 2). Prone position was not performed in any of the included patients during the observation period. 
Table 1

Patients characteristics at ICU admission

\begin{tabular}{|c|c|c|c|c|}
\hline & $\begin{array}{l}\text { Total } \\
(n=60)\end{array}$ & $\begin{array}{l}\text { Automated } P_{\text {cuff }} \\
\text { adjustment } \\
(n=28)\end{array}$ & $\begin{array}{l}\text { Manual } P_{\text {cuff }} \\
\text { adjustment } \\
(n=32)\end{array}$ & $\mathbf{p}$ \\
\hline Age (years) & $\begin{array}{l}55[42- \\
64]\end{array}$ & $57[44-66]$ & $52[42-60]$ & 0.24 \\
\hline Female gender ( $\mathrm{n}[\%])$ & $25(42 \%)$ & $10(36 \%)$ & $15(47 \%)$ & 0.44 \\
\hline Height (cm) & $\begin{array}{l}170 \\
{[162-} \\
175]\end{array}$ & $168[162-180]$ & $\begin{array}{l}170[163- \\
174]\end{array}$ & 0.79 \\
\hline Weight (kg) & $\begin{array}{l}69[59- \\
80]\end{array}$ & 70 [61-77] & $68[58-81]$ & 0.86 \\
\hline BMI & $\begin{array}{l}23.4 \\
{[21.6-} \\
26.7]\end{array}$ & $22.9[19.8-24.8]$ & $\begin{array}{l}24.0[22.5- \\
28.0]\end{array}$ & 0.14 \\
\hline SAPS II & $\begin{array}{l}47[34- \\
60]\end{array}$ & 49 [39-43] & $43[32-58]$ & 0.53 \\
\hline \multicolumn{5}{|l|}{ SOFA score } \\
\hline admission & $8[5-9]$ & $8[6-9]$ & $7[5-10]$ & 0.75 \\
\hline inclusion & $9[7-10]$ & 9 [6-9] & $9[7-11]$ & 0.15 \\
\hline \multicolumn{5}{|l|}{ Reason for ICU admission (n [\%]) } \\
\hline SAH & $26(43 \%)$ & $12(43 \%)$ & $14(44 \%)$ & $\overrightarrow{0.99}$ \\
\hline $\mathrm{ICH}$ & $10(17 \%)$ & $5(18 \%)$ & $5(16 \%)$ & $\overrightarrow{0.99}$ \\
\hline $\begin{array}{l}\text { Post-operative admission after elective } \\
\text { surgery }\end{array}$ & $9(15 \%)$ & $4(14 \%)$ & $5(16 \%)$ & $\overrightarrow{0.99}$ \\
\hline TBI & $6(10 \%)$ & $2(7 \%)$ & $4(13 \%)$ & 0.67 \\
\hline Stroke & $5(8 \%)$ & $2(7 \%)$ & $3(9 \%)$ & $\overrightarrow{0.99}$ \\
\hline Other & $4(7 \%)$ & $3(11 \%)$ & $1(3 \%)$ & 0.33 \\
\hline
\end{tabular}

Legend: BMI: body mass index; SAPS II: simplified acute physiology score; SOFA: sequential organ failure assessment; ICU: intensive care unit; SAH: subarachnoid hemorrhage; ICH: intra-cerebral hematoma; TBI: traumatic brain injury. *Profile ${ }^{\text {TM }}$ Soft-Seal ${ }^{\circledR}$ Cuff, Portex, Smith Medical, MN, USA. 


\begin{tabular}{|c|c|c|c|c|}
\hline & $\begin{array}{l}\text { Total } \\
(n=60)\end{array}$ & $\begin{array}{l}\text { Automated } P_{\text {cuff }} \\
\text { adjustment } \\
(n=28)\end{array}$ & $\begin{array}{l}\text { Manual } P_{\text {cuff }} \\
\text { adjustment } \\
(n=32)\end{array}$ & $\mathbf{p}$ \\
\hline Hypertension & $17(28 \%)$ & $5(18 \%)$ & $12(38 \%)$ & 0.15 \\
\hline Immunocompromised & $1(2 \%)$ & $1(4 \%)$ & 0 & 0.47 \\
\hline Diabetes mellitus & $3(5 \%)$ & $2(7 \%)$ & $1(3 \%)$ & 0.59 \\
\hline $\begin{array}{l}\text { Antimicrobial therapy started within } 48 \mathrm{~h} \\
\text { after tracheal intubation }(\mathrm{n}[\%])\end{array}$ & $15(25 \%)$ & $5(18 \%)$ & $10(31 \%)$ & 0.37 \\
\hline $\begin{array}{l}\text { Endotracheal tube model (n [\%]) } \\
\text { Profile }{ }^{T M} \text { Soft-Seal® Cuff* } \\
\text { Other }\end{array}$ & $\begin{array}{l}37(62 \%) \\
22(38 \%)\end{array}$ & $\begin{array}{l}19(68 \%) \\
9(32 \%)\end{array}$ & $\begin{array}{l}18(56 \%) \\
14(44 \%)\end{array}$ & 0.43 \\
\hline \multicolumn{5}{|l|}{$\begin{array}{l}\text { Intra-hospital transport during the } 48 \text { hour } \\
\text { observation period (n [\%]) }\end{array}$} \\
\hline 1 & $44(77 \%)$ & $18(64 \%)$ & $26(81 \%)$ & 0.02 \\
\hline 2 & $16(27 \%)$ & $6(21 \%)$ & $10(31 \%)$ & 0.55 \\
\hline 3 & $6(10 \%)$ & $4(14 \%)$ & $2(6 \%)$ & 0.40 \\
\hline 4 & $2(3 \%)$ & $1(4 \%)$ & $1(3 \%)$ & 1 \\
\hline MV duration (days) & $\begin{array}{l}14[7- \\
23]\end{array}$ & $17[8-28]$ & $13[7-20]$ & 0.45 \\
\hline Ventilator Free Days & $4[0-8]$ & $5[0-7]$ & $3[0-10]$ & 0.96 \\
\hline Length of stay (days) & $\begin{array}{l}20[11- \\
34]\end{array}$ & $25[11-35]$ & $17[11-28]$ & 0.39 \\
\hline ICU Mortality (n [\%]) & $22(37 \%)$ & $10(36 \%)$ & $12(38 \%)$ & 0.99 \\
\hline
\end{tabular}


Table 2

Clinical data collected, at each $\mathrm{P}_{\text {cuff }}$ manual determination, during the 48 hour observation period.

\begin{tabular}{|c|c|c|c|}
\hline & $\begin{array}{l}\text { Automated adjustment of } \\
P_{\text {cuff }}\end{array}$ & $\begin{array}{l}\text { Manual } \\
\text { Adjustment } \\
\text { of } P_{\text {cuff }}\end{array}$ & p \\
\hline $\begin{array}{l}\text { Assisted Controlled Ventilation } \\
\text { Peak Pressure }\left(\mathrm{cm} \mathrm{H}_{2} \mathrm{O}\right) \\
\text { Plateau Pressure }\left(\mathrm{cm} \mathrm{H}_{2} \mathrm{O}\right)\end{array}$ & $\begin{array}{l}179 / 246(73 \%) \\
27.4 \pm 5.9 \\
13.6 \pm 5.6\end{array}$ & $\begin{array}{l}225 / 277(81 \%) \\
28.3 \pm 7.8 \\
15.4 \pm 5.8\end{array}$ & $\begin{array}{l}0.02 \\
0.18 \\
0.002\end{array}$ \\
\hline $\begin{array}{l}\text { Pressure Support Ventilation } \\
\text { Pressure support }\left(\mathrm{cm} \mathrm{H}_{2} \mathrm{O}\right)\end{array}$ & $\begin{array}{l}67 / 246(27 \%) \\
12.0 \pm 4.1\end{array}$ & $\begin{array}{l}52 / 277(19 \%) \\
13.4 \pm 3.3\end{array}$ & $\begin{array}{l}0.02 \\
0.052\end{array}$ \\
\hline Enteral Feeding & $150 / 246(62 \%)$ & $200 / 277(72 \%)$ & 0.01 \\
\hline $\begin{array}{l}\text { Vomiting since the previous } \mathrm{P}_{\text {cuff }} \\
\text { determination }\end{array}$ & $5 / 246(2 \%)$ & $8 / 277(3 \%)$ & 0.59 \\
\hline Head of bed elevation, degrees & $\begin{array}{l}29 \pm 3 \\
(n=246)\end{array}$ & $\begin{array}{l}29 \pm 5 \\
(n=277)\end{array}$ & 0.97 \\
\hline PEEP & $5.5 \pm 1.6$ & $5.6 \pm 1.4$ & 0.46 \\
\hline RASS & $-5[-5,-4]$ & $-5[-5,-5]$ & 0.08 \\
\hline \multicolumn{4}{|l|}{ Infusion of, n (\%) } \\
\hline Propofol & $21 / 28(75 \%)$ & $24 / 32(75 \%)$ & $>_{0.99}$ \\
\hline Midazolam & $16 / 28(57 \%)$ & $24 / 32(75 \%)$ & 0.18 \\
\hline Sufentanil & $23 / 28(82 \%)$ & $28 / 32(87 \%)$ & 0.72 \\
\hline Sodium thiopental & $4 / 28(14 \%)$ & $6 / 32(19 \%)$ & 0.74 \\
\hline Neuromuscular blocking agent & $6(21 \%)$ & $12(38 \%)$ & 0.26 \\
\hline
\end{tabular}

\section{Primary endpoint}

The rate of patients with at least 1 underinflation episode within the 48 hour observation period was significantly lower with automated $P_{\text {cuff }}$ adjustment than with manual $P_{\text {cuff }}$ adjustment only 5/28 (17.9\% $[95 \% \mathrm{Cl} 7.4-36.0])$ vs. $20 / 32(62.5 \%[95 \% \mathrm{Cl} 45.2-77.1]) ; \mathrm{p}=0.006)($ Fig. 3$)$.

\section{Secondary endpoints}


The rate of patients with at least 1 overinflation episode was similar $(p>0.99)$ in the 2 groups: $3 / 28$ $(10.7 \%[95 \% \mathrm{Cl} 2.9-28.0])$ vs. $4 / 32\left(12.5 \%\right.$ [95\% Cl 4.4-28.7]) with automated $\mathrm{P}_{\text {cuff }}$ adjustment and with manual $P_{\text {cuff }}$ adjustment only, respectively.

Incidence of under- and overinflation episodes. During the 48-hour observation period, mean $\mathrm{P}_{\text {cuff }}$ was higher with the automated $\mathrm{P}_{\text {cuff }}$ adjustment $\left(25.3 \pm 5.0\right.$ vs. $\left.22.9 \pm 4.3 \mathrm{~cm} \mathrm{H}_{2} \mathrm{O} ; \mathrm{p}<0.001\right)$. The incidence of underinflation episodes was significantly lower in the automated $\mathrm{P}_{\text {cuff }}$ adjustment (237 measurements) than in the manual adjustment group ( 269 measurements): $2.1 \%$ [95\% $\mathrm{Cl} 0.3-3.9]$ vs. $14.9 \%[95 \% \mathrm{Cl} 10.3-$ 19.4]; $p<0.001$ (Fig. 4). The incidence of overinflation episodes was similar in the two groups: $1.7 \%$ $[95 \% \mathrm{Cl} 0.5-4.4]$ vs. $1.9 \%[95 \% \mathrm{Cl} 0.7-4.4], \mathrm{p}>0.99$ (Fig. 4).

The rate of $\mathrm{P}_{\text {cuff }}$ adjustments performed -after $\mathrm{P}_{\text {cuff }}$ measurement was lower with the automated $\mathrm{P}_{\text {cuff }}$ adjustment: $55.7 \%$ [95\% Cl 49.4-61.8] vs. $76.6 \%$ [95\% Cl 71.1-81.3]; $p<0.001$. In addition, these adjustments were of lower magnitude in patients with automated $P_{\text {cuff }}$ adjustment (3.6 \pm 4.7 vs. $5.9 \pm$ $\left.4.5 \mathrm{~cm} \mathrm{H}_{2} \mathrm{O} ; \mathrm{p}<0.001\right)$.

Other outcomes. In each group, 8 early respiratory infections occurred in 8 patients yielding an incidence of $29 \%$ and $25 \%$ in the automated and the manual $P_{\text {cuff }}$ adjustment group, respectively $(p=0.78)$. No significant difference was found between the two groups with regard to the following outcomes at the ICU discharge: duration of mechanical ventilation, ventilator free days, length of ICU stay, and ICU mortality (Table 1).

\section{Discussion}

The main finding of this randomized controlled study $\nabla$ coordinated by nurses of two surgical ICUs of the University Hospital of Nantes $\mathbb{Q}$ is that implementing an automated adjustment of $P_{\text {cuff }}$ by the Tracoe Smart Cuff Manager ${ }^{\text {TM }}$ in combination with intermittent manual adjustments was more effective to regulate $\mathrm{P}_{\text {cuff }}$ than a strategy with manual adjustments alone. Indeed, automated adjustment of $\mathrm{P}_{\text {cuff }}$ markedly decreased the rate of patients experiencing at least one underinflation episode and the incidence of detected episodes of underinflation. Importantly, the automated $\mathrm{P}_{\text {cuff }}$ adjustment strategy was not associated with a higher incidence of detected episodes of tracheal cuff overinflation.

Interestingly, despite the randomization, airway pressures were or tended to be higher in patients allocated to undergo manual $P_{\text {cuff }}$ adjustments solely (Table 2). Since airway pressure is transmitted to $P_{\text {cuff }}[13]$, this imbalance could have reduced the incidence of underinflation episodes among patients with manual $\mathrm{P}_{\text {cuff }}$ adjustments solely. In other words, assuming strictly identical airway pressure between the two groups, the protective effect of the Tracoe Smart Cuff Manager ${ }^{\mathrm{TM}}$ against underinflation episodes could have been even more prominent.

To avoid both microaspirations and tracheal damage, achieving a 24-hour balance between under- and overinflation of the tracheal cuff is desirable. The issue is not new. Indeed, from the 1970s, some 
modified endotracheal tubes were released onto the market for this purpose. One of these tubes housed a valve connected to a larger balloon than the standard pilot balloon. This regulating valve aimed at maintaining $\mathrm{P}_{\text {cuff }}$ close to $30 \mathrm{~cm} \mathrm{H}_{2} \mathrm{O}$ [14]. This so-called Lanz system is the forerunner of the Tracoe Smart Cuff Manager ${ }^{\text {TM }}$. One advantage of the latter relies on its ability to be connected to the standard port of most tracheal tube models (contrary to the Lanz system which is natively-embedded into one model of tracheal tube). To the best of our knowledge, no published study evaluated the Tracoe Smart Cuff Manager $^{\text {TM }}$. Overall, devices automatically regulating $\mathrm{P}_{\text {cuff }}$ were surprisingly poorly assessed. Indeed, besides some very preliminary reports of "home-made" devices [15], a dozen studies evaluated whether an automated device connected to the endotracheal tube effectively maintains $P_{\text {cuff }}$ within an acceptable range $(7,8,15,18-24)$. All these previous studies were single-center studies. They were uncontrolled [22], not randomized [17], of limited size (18 patients or less) [8, 16, 20, 22], experimental [13, 21] and/or tested non-commercialized devices $[19,22]$. Although several very different devices have been tested, most of these studies have concluded that maintenance of $\mathrm{P}_{\text {cuff }}$ within the acceptable range was better achieved with an automated rather than an intermittent manual control of $P_{\text {cuff, }}$ especially via the reduction of underinflation episodes. In their hallmark study, Nseir et al. went even further by demonstrating that implementing an automated $\mathrm{P}_{\text {cuff }}$ control reduced both the tracheal level of pepsin (suggesting a reduction of gastric content microaspiration) and the rate of ventilator-associated pneumonia [7]. Importantly, the reduction in the rate of underinflation episodes must not be at the expense of a potentially harmful increase in the rate of overinflation episodes. Unfortunately, one device [8] and possibly another one [19] were associated with a higher rate of $\mathrm{P}_{\text {cuff }}$ episodes above $30 \mathrm{cmH}_{2} \mathrm{O}$ than routine care. Other drawbacks applying to some devices are worth mentioning: they are bulky and/or inconvenient (which encourages their disconnection before patient transport, a procedure at-risk of aspiration of oropharyngeal content), relatively expensive, need electric [16] or gas [23] supply. This may explain the lack of wide clinical use of automated $\mathrm{P}_{\text {cuff }}$ control. The Tracoe Smart Cuff Manager ${ }^{\text {TM }}$ may overcome all these issues.

\section{Limitations of the study}

First, inherently to the nature of the tested intervention, caregivers could not be blinded to the randomization arm.

Second, the study was focused on the specific population of brain injured patients, and we mostly used one model of endotracheal tube. However, this population is of interest in the field of prevention of respiratory infections since it is prone to develop such infections because, among other reasons, prolonged median duration of mechanical ventilation [24, 25]. We therefore believe that focusing on this specific population should be seen as strength rather than limitation of this study. Therefore, relative caution should be exercised before extrapolating our findings to other settings or populations or even to other airway access devices. Furthermore, this population is also particularly prone to be deeply sedated (Table 1). Since the absence of sedation is independently associated with increased risk for cuff 
underinflation [5], one can hypothesize that the adjunction of the Tracoe Smart Cuff Manager ${ }^{\mathrm{TM}}$ to routine care in less sedated patients would have been associated with an even more marked reduction in the incidence of underinflation episodes than that herein reported. This hypothesis remains to be tested.

Third, $P_{\text {cuff }}$ measurements were not collected continuously. Therefore, undetected episodes of under- or overinflation may have been overlooked. This would have impacted our conclusions if these undetected episodes of incorrect $\mathrm{P}_{\text {cuff }}$ were significantly more frequent in the automated adjustment group than in the manual adjustment group, i.e., an imbalance totally opposite to that observed for detected events. This hypothesis is therefore highly unlikely.

Fourth, in patients with automated $\mathrm{P}_{\text {cuff }}$ adjustment but not in patients from routine care group, we used a three-way stopcock. Of note, direct connection of the manometer to the endotracheal tube may be source of air leakage [27]. The use of the three-way stopcock may have limited the air leakage by connecting the manometer before opening the dedicated outlet. Therefore, some patients may have benefitted more from the use of the three-way stopcock than from the use of the Tracoe Smart Cuff Manager ${ }^{\text {rm }}$. We chose to add the three-way stopcock to the Tracoe Smart Cuff Manager ${ }^{\mathrm{TM}}$ in order to avoid its disconnection (and therefore its necessary re-inflation) each time a manometer is connected, i.e., several times a day. This allowed direct $P_{\text {cuff }}$ measurements, i.e., upstream of the Tracoe Smart Cuff Manager ${ }^{\text {TM }}$ rather than using the dedicated inlet of the device (Fig. 1). Of note, the manufacturer proposes the direct connection of the Tracoe Smart Cuff Manager ${ }^{\mathrm{TM}}$ to the tracheal tube with no three-way stopcock, intermittent manometer $\mathrm{P}_{\text {cuff }}$ measurements being then performed via the dedicated inlet. Interestingly, with this latter approach, manometer connection-induced possible air leakage would slightly deflate the inner balloon of the device but, importantly, not the tracheal cuff. Therefore, when using the Tracoe Smart Cuff Manager ${ }^{\text {TM }}$ with a three-way stopcock or not, manometer connection-induced deflation of the tracheal cuff is theoretically reduced. We believe this is a strength of the device. In the present study, using a three-way stopcock in both groups would have been helpful to delineate the specific contribution of the Tracoe Smart Cuff Manager $^{\text {TM }}$ and the three-way stopcock to our findings. However, adding a three-way stopcock to the endotracheal tube when no device for automated adjustment is connected is not recommended $[24,25]$ and is therefore neither wide current practice nor part of our routine care.

Fifth, in this study, manual adjustments were not guided by strict specific rules except correcting a $\mathrm{P}_{\text {cuff }}$ value outside the recommended range of $20-30 \mathrm{cmH}_{2} \mathrm{O}$. Indeed, the decision of manual adjustment and its magnitude tightly depends on previous measurements and adjustments in a given patient. Hence, several manual adjustments have consisted in modifying a $\mathrm{P}_{\text {cuff }}$ value already within this recommended range (from 21 to $27 \mathrm{cmH}_{2} \mathrm{O}$ for instance) in a possibly unduly manner. This may explain the somewhat high incidence of manual adjustments in both groups (56\% in the Tracoe Smart Cuff Manager ${ }^{\text {TM }}$ group vs. $77 \%$ in the routine care group, $p<0.001)$. Since the Tracoe Smart Cuff Manager ${ }^{\mathrm{TM}}$ is able to inflate or deflate the tracheal cuff, these manual adjustments could have been unnecessary in patients equipped with this device. Indeed, less than $4 \%$ of $\mathrm{P}_{\text {cuff }}$ measurements lied outside the recommended range in this group. 
Last, our study was not designed to assess whether the Tracoe Smart Cuff Manager ${ }^{\mathrm{TM}}$ reduces the incidence of ventilator-associated respiratory infections and therefore the ventilator free days, ICU length of stay or even mortality. Indeed, the Tracoe Smart Cuff Manager ${ }^{\text {Tw }}$ was not kept in place throughout the duration of invasive ventilation but only 48 hours in most patients, i.e., just the duration of the study observation period for its primary endpoint. The present study demonstrates that the Tracoe Smart Cuff Manager $^{\mathrm{TM}}$ reduced the incidence of cuff underinflation. Whether this encouraging finding would translate into a reduction in ventilator-associated respiratory infections is not straightforward and deserves a dedicated study [19]. Indeed, a too rapid $\mathrm{P}_{\text {cuff }}$ correction by the automated device may interfere with the self-sealing mechanism of the cuff and may reduce its sealing characteristics, therefore exposing to microaspirations [28]. Interestingly, the Tracoe Smart Cuff Manager ${ }^{\text {TM }}$ houses a valve aiming at slowing down the reaction time before $\mathrm{P}_{\text {cuff }}$ correction but its effectiveness has to be specifically assessed.

Moreover, prevention of ventilator-associated respiratory infections is multifaceted and demonstrating a reduction in their incidence by acting on only one facet (reduction of underinflation episodes) may require a large study size. An ongoing multicenter study testing another pneumatic device may provide further insight on this relevant topic [29].

\section{Conclusion}

By showing that an approach including the Tracoe Smart Cuff Manager ${ }^{\text {TM }}$ allowed a better control of $\mathrm{P}_{\text {cuff }}$ into the recommended range of $20-30 \mathrm{~cm} \mathrm{H}_{2} \mathrm{O}$ as compared with routine care, this study paved the way for a large study specifically addressing whether this device (as part of a multifaceted preventive strategy) is effective in the prevention of ventilator-associated pneumonia.

\section{Abbreviation}

BMl: body mass index

CDC: control disease center

ETT: Endotracheal tube

$\mathrm{ICH}$ : intra-cerebral hematoma

ICU: intensive care unit

MV: mechanical ventilation

$P_{\text {cuff: }}$ endotracheal tube cuff pressure

SAPS II: simplified acute physiology score

SAH: subarachnoid hemorrhage 
SD: standard deviation

SOFA: sequential organ failure assessment

TBI: traumatic brain injury

\section{Declarations}

\section{Ethics approval and consent to participate}

A national ethics committee (Comité de Protection des Personnes, CPP 2017/62) approved the study design. Written and oral inform consent was obtained from each patient or to his next of kin if the patient was not able to consent.

\section{Consent for publication}

Not applicable

\section{Availability of data and materials}

The datasets used and/or analyzed during the current study are available from the corresponding author on reasonable request.

\section{Competing interests}

Jérôme Dauvergne has no conflict of interest in connection with the work submitted. In addition, JD received, during the past 5 years, travel fees from HALYARD (once in 2016).

Anne-Laure Geffray has no conflict of interest in connection with the work submitted.

Bertrand Rozec has no conflict of interest in connection with the work submitted. In addition, BR received, during the past 5 years, lecture fees from Fisher\&Paykel, Baxter, LFB, Aspen, research grants from Baxter and consulting fees from LFB, Astra Zeneca.

Karim Asehnoune received fees from Fisher Paykel, LFB, Fresenius, Edwards (outside the submitted work).

Karim Lakhal has no conflict of interest in connection with the work submitted. In addition, KL received, during the past 3 years, lecture fees from MEDTRONIC (once, in 2017), congress registration fees from SANOFI AVENTIS (once in 2018), travel fees from MSD France (once, in 2017), NOVEX PHARMA (once, in 2016), GILEAD SCIENCES (twice, 2016 and 2017), PFIZER (once, in 2019).

\section{Funding}


This study was fully funded by TRACOE Medical GmbH, prior to its conduction. The Tracoe Smart Cuff Manager $^{\mathrm{TM}}$ was also provided by TRACOE Medical $\mathrm{GmbH}$. This company has not interfered in the design, conduct and data analysis of the study. None of the investigators has any direct conflict of interest with the company. The financial relationship only involved the institutional research department.

\section{Authors' contributions}

Conception and design: JED, KL.

Collection of data: JED, ALG.

Statistical analysis: JED, KL.

Drafting and revision of the manuscript: JED, KL, BR, KA

\section{Acknowledgements}

We are grateful to Mrs. Laurence Pacaud and Mrs. Sylvie Le Guillou, research nurses, and Mrs. Emmanuelle Cartron, nurse research coordinator, for their important contribution to this work. We are indebted to the Critical Care nurses and all the medical staff of our department of Anaesthesia and Critical Care Medicine.

\section{References}

1. Guidelines for the Management of Adults with Hospital-acquired, Ventilator-associated, and Healthcare-associated Pneumonia. American Journal of Respiratory and Critical Care Medicine. 2005;171:388-416.

2. Rello J, Sonora R, Jubert P, Artigas A, Rué M, Vallés J. Pneumonia in intubated patients: role of respiratory airway care. American journal of respiratory and critical care medicine. 1996;154:111115.

3. Seegobin RD, Hasselt GLV. Endotracheal cuff pressure and tracheal mucosal blood flow: endoscopic study of effects of four large volume cuffs. BMJ. 1984;288:965-8.

4. Touat L, Fournier C, Ramon P, Salleron J, Durocher A, Nseir S. Intubation-related tracheal ischemic lesions: incidence, risk factors, and outcome. Intensive Care Medicine. 2013;39:575-82.

5. Nseir S, Brisson H, Marquette C-H, Chaud P, Di Pompeo C, Diarra M, et al. Variations in endotracheal cuff pressure in intubated critically ill patients: prevalence and risk factors. Eur J Anaesthesiol. 2009;26:229-34.

6. Okgun Alcan A, Yavuz van Giersbergen M, Dincarslan G, Hepcivici Z, Kaya E, Uyar M. Effect of patient position on endotracheal cuff pressure in mechanically ventilated critically ill patients. Australian Critical Care. 2017;30:267-72. 
7. Nseir S, Zerimech F, Fournier C, Lubret R, Ramon P, Durocher A, et al. Continuous Control of Tracheal Cuff Pressure and Microaspiration of Gastric Contents in Critically III Patients. American Journal of Respiratory and Critical Care Medicine. 2011;184:1041-7.

8. Nseir S, Rodriguez A, Saludes P, De Jonckheere J, Valles J, Artigas A, et al. Efficiency of a mechanical device in controlling tracheal cuff pressure in intubated critically ill patients: a randomized controlled study. Annals of Intensive Care. 2015;5.

9. Ferrer M, Torres A. Maintenance of tracheal tube cuff pressure: where are the limits? Critical Care. 2008;12:106.

10. Moher D, Hopewell S, Schulz KF, Montori V, Gotzsche PC, Devereaux PJ, et al. CONSORT 2010 Explanation and Elaboration: updated guidelines for reporting parallel group randomised trials. BMJ. 2010;340:c869-c869.

11. Letvin A, Kremer P, Silver PC, Samih N, Reed-Watts P, Kollef MH. Frequent Versus Infrequent Monitoring of Endotracheal Tube Cuff Pressures. Respiratory Care. 2018;63:495-501.

12. Quenot J-P, Milési C, Cravoisy A, Capellier G, Mimoz O, Fourcade O, et al. Transport intrahospitalier des patients à risque vital (nouveau-né exclu). Recommandations formalisées d'experts sous l'égide de la Société de réanimation de langue française (SRLF), de la Société française d'anesthésie et de réanimation (SFAR) et de la Société française de médecine d'urgence (SFMU). Réanimation. 2011;20:361-6.

13. Chenelle CT, Oto J, Sulemanji D, Fisher DF, Kacmarek RM. Evaluation of an Automated Endotracheal Tube Cuff Controller During Simulated Mechanical Ventilation. Respiratory Care. 2015;60:183-90.

14. Haas CF, Eakin RM, Konkle MA, Blank R. Endotracheal Tubes: Old and New. Respiratory Care. 2014;59:933-55.

15. Abdelatti MO. A cuff pressure controller for tracheal tubes and laryngeal mask airways. Anaesthesia. 1999;54:981-6.

16. Rouzé A, De Jonckheere J, Zerimech F, Labreuche J, Parmentier-Decrucq E, Voisin B, et al. Efficiency of an electronic device in controlling tracheal cuff pressure in critically ill patients: a randomized controlled crossover study. Annals of Intensive Care. 2016;6.

17. Lorente L, Lecuona M, Jiménez A, Lorenzo L, Roca I, Cabrera J, et al. Continuous endotracheal tube cuff pressure control system protects against ventilator-associated pneumonia. Crit Care. 2014;18:R77.

18. Jaillette E, Zerimech F, De Jonckheere J, Makris D, Balduyck M, Durocher A, et al. Efficiency of a pneumatic device in controlling cuff pressure of polyurethane-cuffed tracheal tubes: a randomized controlled study. BMC Anesthesiology. 2013;13.

19. Valencia M, Ferrer M, Farre R, Navajas D, Badia JR, Nicolas JM, et al. Automatic control of tracheal tube cuff pressure in ventilated patients in semirecumbent position: A randomized trial*: Critical Care Medicine. 2007;35:1543-9.

20. Duguet A, D’Amico L, Biondi G, Prodanovic H, Gonzalez-Bermejo J, Similowski T. Control of tracheal cuff pressure: a pilot study using a pneumatic device. Intensive Care Medicine. 2007;33:128-32. 
21. Nseir S, Duguet A, Copin M-C, De Jonckheere J, Zhang M, Similowski T, et al. Continuous control of endotracheal cuff pressure and tracheal wall damage: a randomized controlled animal study. Crit Care. 2007;11:R109.

22. Farre $R$, Rotger $M$, Ferrer $M$, Torres $A$, Navajas $D$. Automatic regulation of the cuff pressure in endotracheally-intubated patients. European Respiratory Journal. 2002;20:1010-3.

23. Miller DM. A pressure regulator for the cuff of a tracheal tube. Anaesthesia. 1992;47:594-6.

24. Asehnoune, K., Roquilly, A. \& Cinotti, R. Respiratory Management in Patients with Severe Brain Injury. Crit Care 22, 76 (2018) doi:10.1186/s13054-018-1994-0

25. Geeraerts T, Velly L, Abdennour L, Asehnoune K, Audibert G, Bouzat P, et al. Management of severe traumatic brain injury (first 24 hours). Anaesthesia Critical Care \& Pain Medicine. 2018;37:171-86.

26. Roquilly A, Feuillet F, Seguin P, Lasocki S, Cinotti R, Launey Y, et al. Empiric antimicrobial therapy for ventilator-associated pneumonia after brain injury. European Respiratory Journal. 2016;47:1219-28.

27. Aeppli N, Lindauer B, Steurer MP, Weiss M, Dullenkopf A. Endotracheal tube cuff pressure changes during manual cuff pressure control manoeuvres: An in-vitro assessment. Acta Anaesthesiol Scand. 2018;63:55-60.

28. Weiss M, Doell C, Koepfer N, Madjdpour C, Woitzek K, Bernet V. Rapid pressure compensation by automated cuff pressure controllers worsens sealing in tracheal tubes. British Journal of Anaesthesia. 2009;102:273-8.

29. Marjanovic N, Frasca D, Asehnoune K, Paugam C, Lasocki S, Ichai C, et al. Multicentre randomised controlled trial to investigate the usefulness of continuous pneumatic regulation of tracheal cuff pressure for reducing ventilator-associated pneumonia in mechanically ventilated severe trauma patients: the AGATE study protocol. BMJ Open. 2017;7:e017003.

\section{Figures}




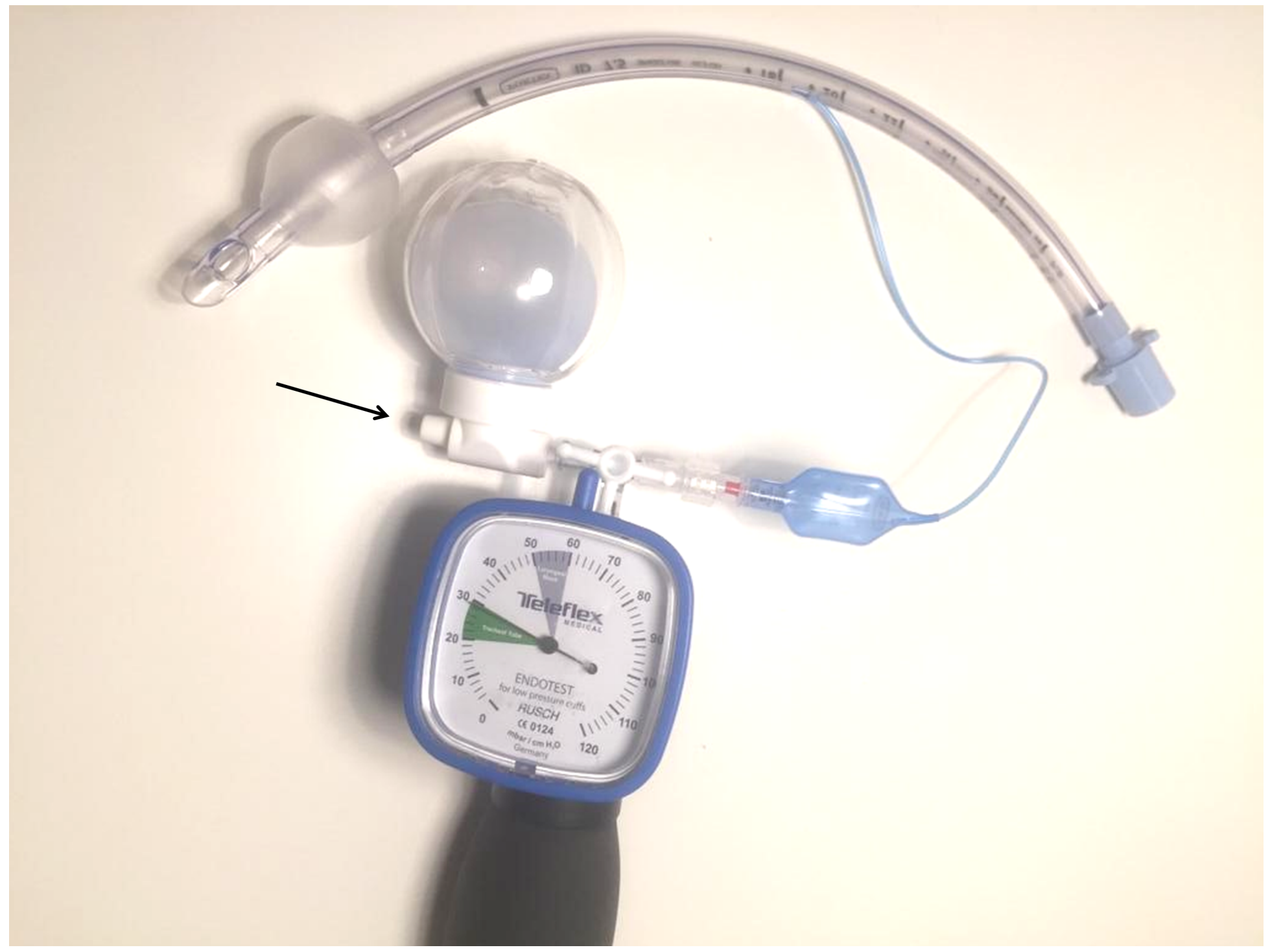

Figure 2

The Tracoe Smart Cuff Manager ${ }^{\mathrm{TM}}$ Legend: This figure displays the Tracoe Smart Cuff Manager ${ }^{\mathrm{TM}}$ and our routine care manual manometer, the latter being only intermittently connected to the former. The Tracoe Smart Cuff Manager ${ }^{\text {TM }}$ houses a blue inner balloon protected by a rigid transparent sphere. This blue balloon keeps the tracheal cuff pressure (Pcuff) within the $20-30 \mathrm{~cm} \mathrm{H} 20$ range. Indeed, if Pcuff is high, air is transferred from the tracheal cuff to the blue inner balloon and vice-versa if Pcuff is low.

Beforehand, the blue balloon is inflated, via the air inlet (arrow), by a healthcare provider using a syringe to a volume representing $\otimes$ to $3 / 4$ of the volume of the transparent rigid sphere (this represents the injection of about $60 \mathrm{~mL}$ of air). When the quick visual inspection (for example, at each healthcare provider visit) indicates that the volume of the blue balloon has decreased (< half the volume of the transparent sphere), the blue balloon has to be reinflated. The Tracoe Smart Cuff Manager ${ }^{\mathrm{TM}}$ also houses a valve which aims at slowing down the reaction time in order to respect the tracheal cuff intrinsic sealing properties [28]. Thus, in this study, we chose to measure Pcuff upstream of the Tracoe Smart Cuff Manager ${ }^{\text {TM }}$ rather than using the dedicated air inlet of the device (arrow). Hence, for this study, the Tracoe Smart Cuff Manager ${ }^{\mathrm{TM}}$ 


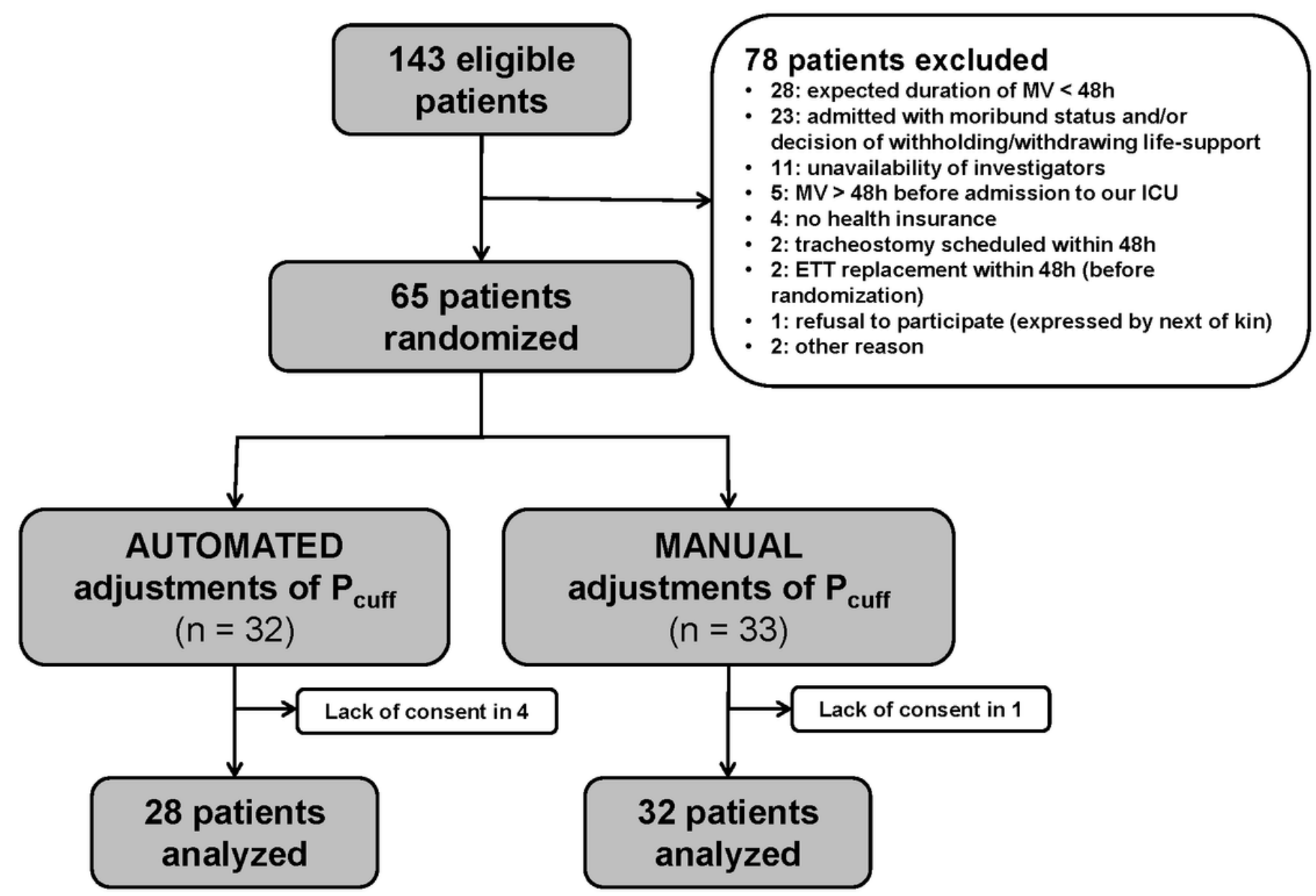

237 measurements of $P_{\text {cuff }}$

269 measurements of $P_{\text {cuff }}$

Figure 4

Study flow chart Legend: MV: mechanical ventilation; ICU: intensive care unit; ETT: Endotracheal tube; Pcuff: endotracheal tube cuff pressure. Eligible patients were patients admitted to the ICU for acute brain injury and invasive mechanical ventilation. 


\section{At least 1 detected episode of underinflation}

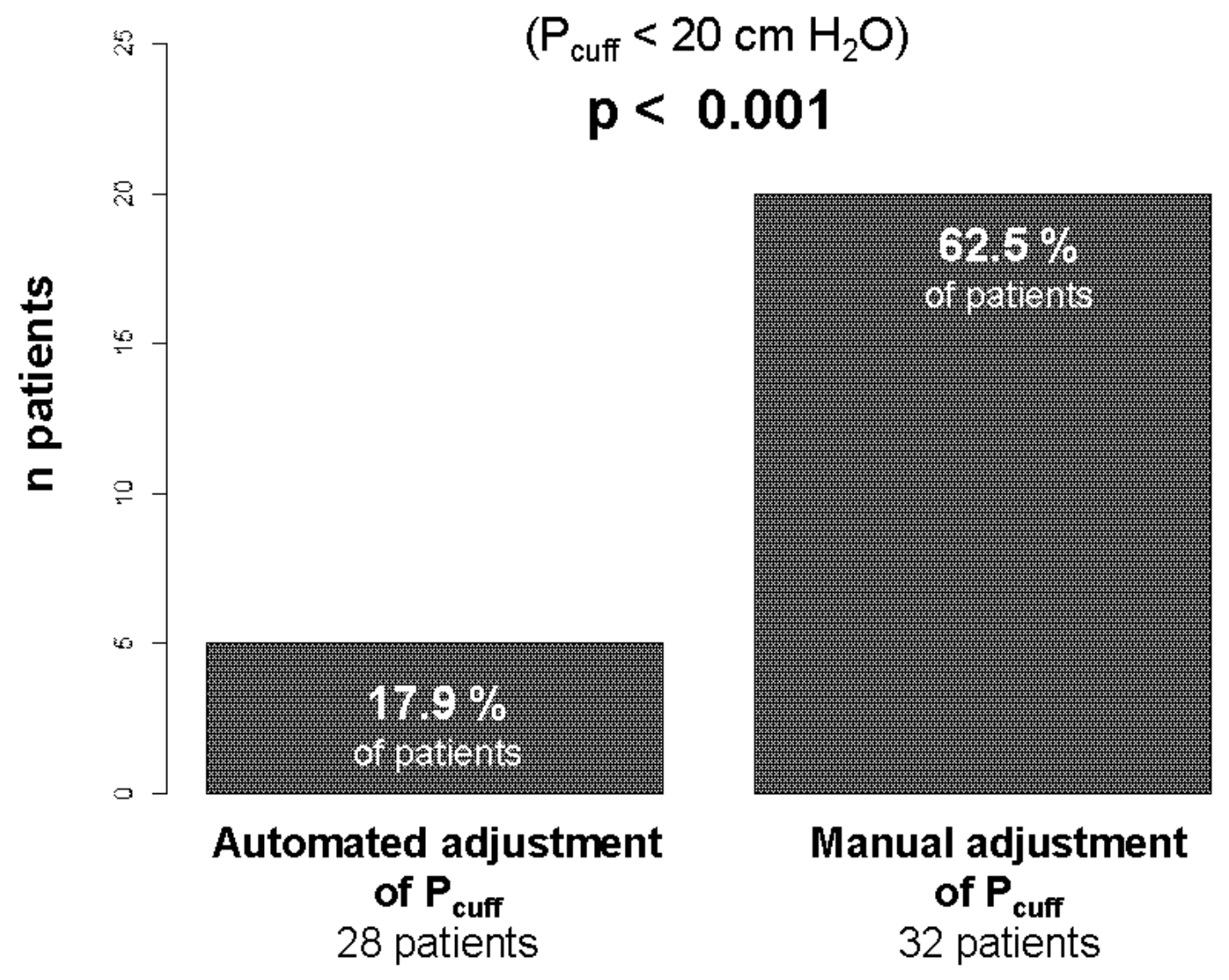

Figure 6

Impact of the Pcuff adjustment technique on the occurrence of at least one underinflation episode. Legend: Pcuff: cuff pressure. An underinflation episode corresponds to Pcuff $<20 \mathrm{~cm} \mathrm{H} 2 \mathrm{O}$. 


\section{Under- and overinflation episodes}
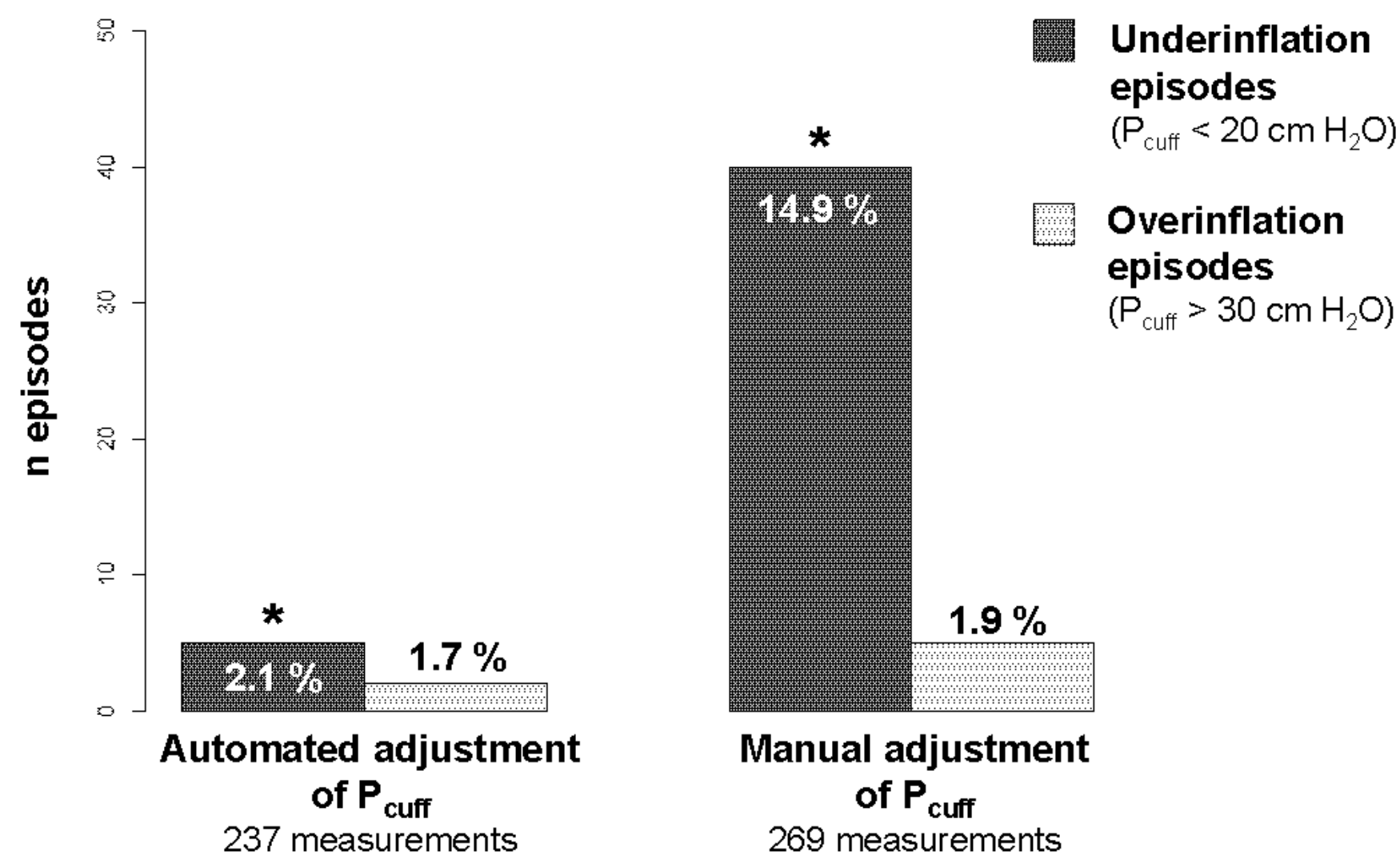

Figure 8

Incidence of under- and overinflation episodes with respect to the Pcuff adjustment strategy. Legend:

Pcuff: cuff pressure. An underinflation episode corresponds to Pcuff $<20 \mathrm{~cm} \mathrm{H} 2 \mathrm{O}$, overinflation episode corresponds to Pcuff $>30 \mathrm{~cm} \mathrm{H} 2 \mathrm{O}$. $*$ : $p<0.001$ for the comparison of underinflation episodes between the two groups. 